\title{
Modules and Analysis of Technological Parameter Optimization for Surface Pretreatment with Sandblasting on Wind Turbine Blades
}

\author{
Yu Xiangyong, Wei Xiuting*, Huang Xuemei and Zhang Lei’an \\ School of Mechanical Engineering, Shandong University of Technology, China
}

Received 4 March 2020; Accepted 15 May 2020

\begin{abstract}
At present, the prevailing technology used in sandblasting for wind turbine blades is manual sandblasting. Such technology is affected by various technological parameters, its optimal technological parameters are hard to be determined, and its sandblasting efficiency is low because blade sandblasting is a process of gas-solid coupling. A mathematical jet model and a simulation module for liquid-solid coupling were presented in this study to reveal the relationship among technological parameters, surface roughness, and sandblasting efficiency. A mathematical jet model for the blade surface sandblasting system was established on the basis of Bernoulli's equation and Avrami formula. In such a model, the pressure at the inlet and the particle diameter were identified as key parameters that affect the particle velocity during sandblasting on blade surfaces. The relation of the characteristics between sandblasting velocity and surface roughness was confirmed, and the sandblasting efficiency was ensured to meet the sandblasting coverage rate. A simulation model for liquid-solid coupling was established using FLUENT software, and various simulation results of gas-solid biphasic flow fields and change curves of the particle velocity were analyzed. Finally, sandblasting experiments on blade surfaces were carried out. The surface micro morphology of several sets of blades was analyzed using a scanning electron microscope, and the accuracy of the model was verified. Results show that a positive relationship exists between the pressure at inlet and particle diameter and sandblasting roughness within a certain range. The pressure at the inlet and the particle diameter can affect the sandblasting efficiency. The fourth group of technological parameters is proven to be an optimal technological parameter combination of sandblasting through 12 groups of orthogonal tests. This study provides a certain reference for studying the relationship among the characteristic parameters of blade material surfaces and technological parameters for sandblasting, enhancement of blade sandblasting efficiency, and optimization decision-making for technological parameters for sandblasting.
\end{abstract}

Keywords: Wind turbine blades, Blade sandblasting, Mathematical jet model, Technological parameters for sandblasting

\section{Introduction}

Most wind turbine blades are installed in windy, sandy, and oceanic areas. A uniformly distributed coating surface with a strong adhesion can provide favorable protection for blades against an extreme environment. The surfaces of demolded blades are smooth. Treatment on the blades' surfaces is required to meet the requirements of surface roughness in the subsequent painting process; therefore, surface pretreatment is the key process that affects the adhesion of blade coating. Pneumatic sandblasting is a processing technology that jets the abrasive accelerated by compressed air onto the surface of materials to achieve the objective of surface treatment on the workpiece surface. Pneumatic sandblasting is broadly applied in aircraft sandblasting pretreatment, the coating on hulls for rust prevention, and stress pretreatment on the metal surfaces and other fields due to its characteristics. These characteristics include high processing efficiency, uniform distribution of characteristic parameters on the treated surfaces, and easy control of technological parameters.

However, manual pneumatic sandblasting is commonly used in the manufacturing process of wind turbine blades.

*E-mail address: yuxiangyong1314@163.com

ISSN: 1791-2377 @ 2020 School of Science, IHU. All rights reserved. doi:10.25103/jestr.133.23
The efficiency of this mechanism is low, and its quality is hard to ensure. The surface morphology of the sandblasted wind turbine blades is relevant to several groups of technological parameters. Hence, manual parameter optimization and precise control are difficult. Manual works may result in excessive or insufficient sandblasting and affect the quality of the wind turbine blades.

Based on the above-mentioned conditions, theoretical studies are carried out by scholars on the characteristic parameters of the sandblasted material surfaces [1][2]. However, all of these studies have laid special emphasis on the velocity of abrasive. However, the same velocity of abrasive may be formed by various technical parameters, which make the surface characteristic parameters to be not necessarily the same. In recent years, many scholars have successively studied the law of the influences by various technological parameters on the surface characteristic parameters of materials through experiments. However, the testing methods cannot verify all possibilities. Therefore, the problem to be solved is as follows: how to accurately predict the optimal technological parameters of pneumatic sandblasting for wind turbine blades and define the relationship between technological parameters and the surface morphology of wind turbine blades for the pretreatment technology of wind turbine blades.

To this end, a computational and mathematical jet model for sandblasting on wind turbine blades is established in this 
study through velocity analysis, coverage rate analysis, and FLUENT simulation. This model is used to analyze the sandblasting technological parameters, particle velocity, and coverage rate, which are designed to predict the coupling relationship among the sandblasting technological parameters, particle velocity, and coverage rate in a precise way. Thus, a reference is provided for the development of the surface sandblasting systems and optimization of the technological parameters for wind turbine blades.

\section{State of the art}

At present, numerous studies were conducted by scholars on issues of pneumatic sandblasting and gas-solid biphasic coupling. Huang [3] provided a new method that utilized a discrete phase model (DPM) to simulate the velocity flow field on the basis of a computational fluid dynamic (CFD) method. However, this method lacked explicit scientific analysis on the characteristics of fluid outside of the nozzles. Li[4] explored the influences brought by several groups of technological parameters on the surface roughness of the metal workpieces in the way of experiments. However, her method could not completely suit the composite materials, such as wind turbine blades. Wang [5] selected 3D roughness parameters that could represent the optimal technological parameters through multiscale analyses on the surface morphology of the test pieces. However, the author failed to point out the mathematical relationship between the technological parameters and the morphological features. Liao[6] analyzed the influences brought by various sandblasting surface coverage rates on the surface integrity of 7075 aluminum alloy through stress tests, hardness tests, scanning electron microscopy (SEM) observation, and surface roughness experiments. Nevertheless, the author failed to expound the coupling relationship between the technological parameters and the coverage rate. Zhang [7] explained the influences of different individual variables on the coverage rate under the same conditions through experiments but failed to elaborate on the mathematical relationship between coverage rate and roughness. Wang Keyin[8] conducted numerical simulation on the related flow fields of nozzles with FLUENT software and proposed that a de Laval nozzle could provide the gas flow passing through it a supersonic speed. Luo[9] established a EulerLagrange numerical biphasic flow model and analyzed the particle distribution of gas-solid biphasic fields on the basis of the CFD methods. With regard to the issue of the coverage rate during pneumatic shot blasting, Kirk[10] and Abyaneh[11] considered the proportion of the crater area in the target panel and presented an Avrami formula for predicting the coverage rate, but they did not point out the handling methods for nongeometric solids, such as abrasive particles. Suyitno[12] believed that sandblasting could increase the surface roughness of the metal and composite materials through microhardness distribution and tensile tests but did not state the increase mechanism of roughness. With regard to the issue of parameter optimization of the gas-solid biphasic flow, Hensel[13] analyzed the influences brought by various technological parameters on the surface treatment on the materials during shot blasting. Meanwhile, the author pointed out the similarity and referenceability of sand and shot blasting and established a related model for the specific representation. Dongmyung[14] indicated a method for keeping the evenness and coverage rate during shot blasting and improved the shot blasting efficiency through the discrete element method. However, the author did not establish the relationship between the coverage rate and sandblasting efficiency. Singh [15] adopted experimental and X-ray methods to study the influences of sandblasting on the surface roughness of materials and provided a basis for optimization of the micro sandblasting technique and pressure control. Draganovská [16][17] obtained a set of roughness parameters that could be used to evaluate the sandblasted surface through the establishment of a correlation matrix and on the basis of the analytical results.

The above-mentioned studies were mainly focused on the gas-solid biphasic coupling issues in the field of machinery. Most such studies are carried out through experiments. Few studies are carried out in the field of composite materials. In particular, studies with regard to the mechanism of sandblast grinding on the surfaces of the wind turbine blades are rare. A mathematical jet model for the blade surface sandblasting system is established in this study on the basis of Bernoulli's equation and Avrami formula. In such a model, a series of key parameters that affect the particle velocity during sandblasting on the blade surfaces were obtained. The sandblasting efficiency is ensured to meet the sandblasting coverage rate. A simulation model for liquid-solid coupling was established with FLUENT software, various simulation results of change curves of particle velocity, and blade surfaces eroded by particles under various technological parameters during sandblasting on the blade surfaces. Finally, experiments of sandblasting on the blade surfaces were carried out, the surface micro morphology of several sets of blades is analyzed using a SEM, and adhesion tests are carried out. The results in this study provide a certain reference for examining the relationship between the characteristic parameters of the blade material surfaces and the technological parameters for sandblasting, enhancement of the blade sandblasting efficiency, and optimization decision making for the technological parameters for sandblasting.

The remainder of this study is organized as follows: In Section 3, the structure of an automatic sandblasting system for wind turbine blades is described, and a mathematical jet model is constructed. In Section 4, the influencing characteristics of the technological parameters on this model are analyzed by using a simulation model for the hydrodynamics and SEM tests, and mechanism of action and the influencing characteristics brought by the technological parameters of sandblasting on the micro morphology of wind turbine blade surfaces under various working conditions are obtained. Section 5 provides a summary and conclusion of this study.

\section{Methodology}

\subsection{Physical model}

Fig. 1 shows the surface sandblasting system for wind turbine blades. Fig. 2 depicts the appearance of the nozzle for sandblasting. Fig. 3 shows a drawing of the particle movement inside the nozzle.

One set of surface sandblasting system for the wind turbine blades was designed to realize the automation of sandblasting. Table 1 shows the design parameters. 


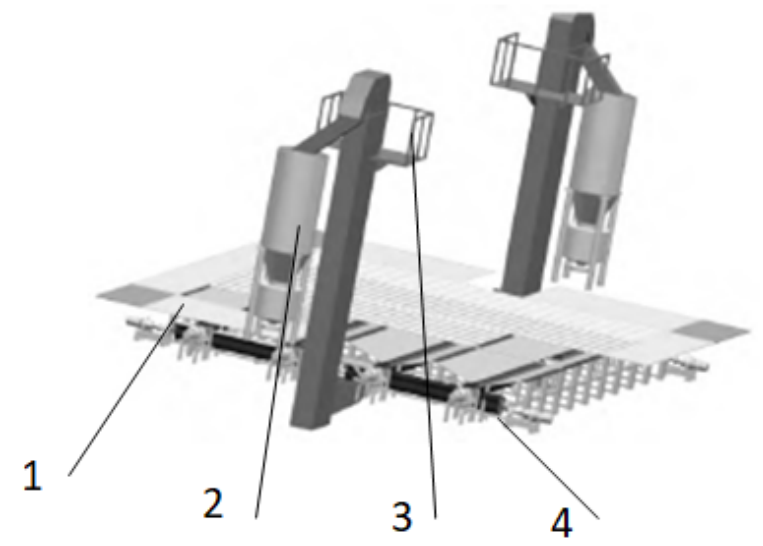

Fig. 1. Surface sandblasting system for wind turbine blades 1-Travelling mechanism; 2-sand blaster; 3-observation platform; 4retractor mechanism

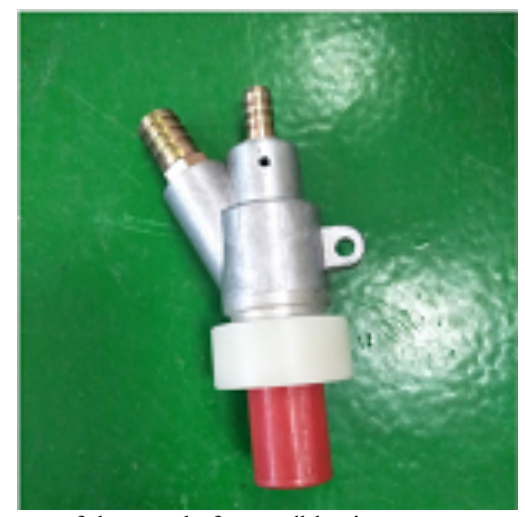

Fig. 2. Appearance of the nozzle for sandblasting

Nozzle

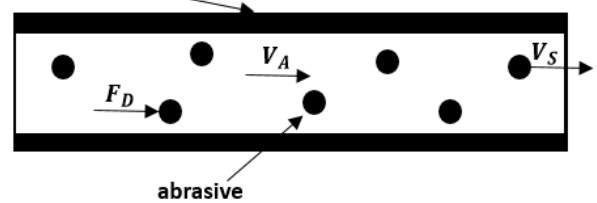

Fig. 3. Drawing of particle movement inside the nozzle

Table 1.Calculation parameters of the collision model

\begin{tabular}{c|c|c|c|c|c|c|c}
\hline \multicolumn{7}{|c|}{ Nominal parameter } & Geometric parameter \\
\hline Volume & Nozzle dia. & Abrasive dia. & $\begin{array}{c}\text { Handling } \\
\text { velocity } \\
1 \mathrm{~m}^{3}\end{array}$ & Airflow rate & $\begin{array}{c}\text { Pressure } \\
\text { of air } \\
\text { source } \\
5-8 \mathrm{bar} \\
\left(\mathrm{kg} / \mathrm{cm}^{2}\right)\end{array}$ & $\begin{array}{c}\text { Total power } \\
\text { of equipment }\end{array}$ & Dimensions of workpiece \\
$7 \mathrm{KW}$ & $0.5-1.2 \mathrm{~mm}$ & $20-30 \mathrm{~m}^{2} / \mathrm{h}$ & $8 \mathrm{~m}^{3} / \mathrm{min}$ & $3000 \mathrm{~mm} \times 1300 \mathrm{~mm} \times 650 \mathrm{~mm}$ \\
\hline
\end{tabular}

\subsection{Selection of biphasic flow simulation models for pneumatic sandblasting}

A suitable biphasic flow simulation model must be selected to analyze the gas-solid biphasic flow fields inside and outside a nozzle, and computational fluid dynamic software must be used for the simulation analysis of several factors of the flow field. Accordingly, the characteristic parameters of air inside and outside a nozzle vary, and a suitable biphasic model needs to be determined on the basis of the characteristic parameters of the gas-solid biphasic flow inside and outside of a nozzle. In accordance with the respective features of various theoretic models for the gassolid biphasic flow adopted in the Euler-Lagrange method and Euler-Euler approach, the particle loading rate $\beta$ and Stokes number St must be calculated to determine a biphasic flow model [18] as per the basic requirements of the gasliquid biphasic flow in the pneumatic sandblasting system studied herein. Table 2 shows the calculation parameters for the collision model, and Table 3 shows the calculation of the collision model.

Table 2.Calculation parameters of the collision model

\begin{tabular}{c|c}
\hline Parameter & Actual value \\
\hline Initial temperature of the compressed air & $300 \mathrm{~K}$ \\
Atmospheric temperature & $300 \mathrm{~K}$ \\
Density of the compressed air & $7.058 \mathrm{~kg} / \mathrm{m}^{3}$ \\
Atmospheric pressure & $1.01 \times 105 \mathrm{~Pa}$ \\
Air density & $1.225 \mathrm{~kg} / \mathrm{m}^{3}$ \\
Particle density & $2,600 \mathrm{~kg} / \mathrm{m}^{3}$ \\
\hline
\end{tabular}

Table. 3.Calculation of the collision model

\begin{tabular}{l|l}
\hline Parameter & Actual value \\
\hline Volume flowrate of air in a unit time & $364.2 \mathrm{~m}^{3} / \mathrm{h}$ \\
Volume flowrate of particles in a unit time & $0.215 \mathrm{~m}^{3} / \mathrm{h}$ \\
Mass loading rate in the compressed air environment & 1.26 \\
Mass loading rate in the atmospheric environment & 1.26 \\
$\begin{array}{l}\text { Volumetric loading rate in the compressed air } \\
\text { environment }\end{array}$ & $3.4 \times 13$ \\
$\begin{array}{l}\text { Volumetric loading rate in the atmospheric } \\
\text { environment }\end{array}$ & $5.9 \times 14$ \\
$\begin{array}{l}\text { Average interval of particles in the compressed air } \\
\text { environment }\end{array}$ & 5.36 \\
$\begin{array}{l}\text { Average interval of particles in the atmospheric } \\
\text { environment }\end{array}$ & 9.61 \\
\hline
\end{tabular}

The calculations of the collision model in Table 2 demonstrate that during sandblasting on wind turbine blades, the mass and volumetric loading rates of the airborne particles in the compressed air environment inside the nozzle, and those in the atmospheric environment outside of the nozzle are small. The average interval of particles is large, that is, the particles are isolated from each other, and mutual collision among particles is negligible. This phenomenon is a flowing mode of the particles, and the volumetric loading rate is small. The action of the fluid on the particles is considered. The effects of particles on the fluid are neglected. An Euler-Lagrange method-based DPM is adopted.

\subsection{Establishment of a mathematical model for particle velocity and jet}

A mathematical jet model for the biphasic flow of pneumatic sandblasting must be established to provide a theoretical basis for the subsequent simulation and experiments. This 
work is carried out to analyze the technical parameters that will influence the effect of sandblasting on the wind turbine blades and its mathematical model.

During sandblasting, the driving force borne by particles FD is directly proportional to the square of speed difference of the gas-solid biphasic flow, airflow density, and the area of the thrust surface of particles [19]. The driving force of the airflow borne by particles FD is indicated in Equation (1).

$$
F_{D}=\frac{1}{2} \varepsilon C_{D} A_{s} \rho_{A}\left(V_{A}-V_{s}\right)^{2}
$$

Where $\varepsilon$ is the correction factor of the surface morphology depending on the material type, surface area, and mass of particles, and its value range is $0.5-1.1 ; C_{D}$ is the drag coefficient; $A_{s}$ is the area of the thrust surface of the unit abrasive particles; $\rho_{A}$ is the gas density.

The collision among the abrasive particles is random, and their individual mass is light. Thus, mutual collision among particles and their action of gravity is neglected.

The gas used for pneumatic sandblasting is compressed air. Hence, Bernoulli's equation of compressible fluid is used as the function of the pressure ratio to gain the theoretical airflow inside the nozzle (Equation (2)).

$$
V_{A L}=\left(2 \frac{k}{k-1} \frac{P}{\rho_{A}}\left[1-\left(\frac{P_{0}}{P}\right)^{\frac{k-1}{k}}\right]\right)^{1 / 2}
$$

Where $k$ is the adiabatic exponent, which is related to the gas type, withstanding the pressure and temperature; $P_{0}$ is the standard atmospheric pressure; and $P$ is the absolute pressure inside the nozzle.

Kalide et al. [20] reported that the airflow velocity in a nozzle is affected by its geometry and dimensions. The actual velocity of the airflow inside the nozzle after correction $V_{A}$ is as follows:

$$
V_{A}=\varphi_{L} V_{A L}
$$

where $\varphi_{L}$ is the correction factor of gas velocity (depending on the dimensionless parameters of the nozzle shape and air pressure of nozzle; for smooth cylindrical nozzles $\varphi_{L} \approx 0.9$ ).:

An unsurpassable limit of wind velocity $V_{L}$ exists for cylindrical nozzles. The limit of wind velocity $V_{L}$ is shown in Equation (4).

$V_{L}=\left(\frac{2 k}{k+1} R_{i} T\right)^{1 / 2}$

Under the action of the driving force $F_{D}$, the movement process of the abrasive particles follows Newton's second law of motion. After substitution of Newton's law into Equation (1), the movement process is shown in Equation (5). $m_{s} \frac{d v_{s}}{d t}=F_{D}=\varepsilon C_{D} A_{s} \frac{\rho_{A}}{2}\left(V_{A}-V_{s}\right)^{2}$

where $m_{s}$ is the unit weight of the abrasive.

The cross-sectional area of the abrasive particles $A_{s}$ is shown in Equation (6).

$A_{s}=\frac{\pi d_{s}^{2}}{4}$

Where $d_{s}$ is the equivalent volume diameter of the abrasive particles, which follows the Rosin-Rammler distribution.

The unit mass of the abrasive particles $m_{s}$ is shown in Formula (7).

$m_{s}=\frac{\pi d_{s}^{3} \rho_{s}}{6}$

In combination with the above-mentioned formula, the abrasive particles inside the nozzle $V_{s}$ are shown in Formula (8).

$$
V_{s}=\left(\frac{3 \varepsilon C_{D} \rho_{A} l_{n}}{2 d_{s} \rho_{s}}\right)^{1 / 2}\left(V_{A}-V_{s}\right)
$$

where $l_{n}$ is the length of the nozzle.

The compressed air left the nozzle and then entered the atmospheric environment. The air components are the same. Therefore, the airflow motion of the compressed air belongs to the free air jet. The airflow outside the nozzle gradually evolved into two zones: potential core zone and main zone. Fig. 4 shows a nonchemical diagram of the free air jet.

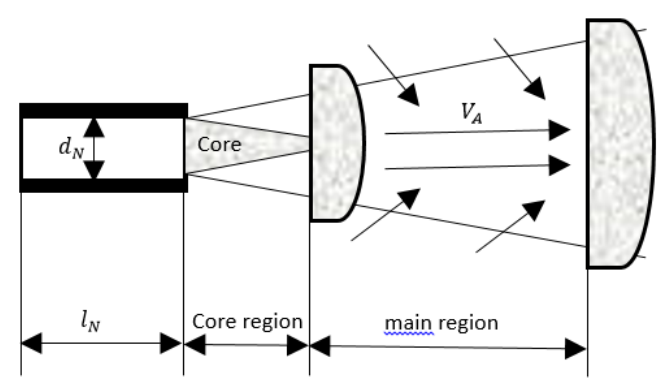

Fig. 4. Nonchemical sketch map of the free air jet

The wind velocity at the centerline after the nozzle $V_{A}^{x}$ is as follows:

$V_{A}^{x}= \begin{cases}V_{A}^{n} & x \leq 6.2 d_{n} \\ V_{A}^{n}\left(\frac{6.2 d_{n}}{x}\right) & x>6.2 d_{n}\end{cases}$

where $\mathrm{x}$ is the axial distance between the abrasive and the outlet of the nozzle; and $d_{n}$ is the diameter of the nozzle.

The equal interval method and iterative approach were used to obtain the velocity at the interval. Lastly, the fullprocess velocity function of the abrasive particles is as follows: 


$$
V_{s}^{i}=\left\{\begin{array}{l}
{\left[\left(V_{s}^{i-1}\right)^{2}+\frac{3 \varepsilon \rho_{A}^{N} l_{s}}{2 d_{s} \rho_{s}}\left(V_{a}^{N}-V_{s}^{i-1}\right)^{2}\right]^{1 / 2} V_{s}^{i-1} \leq V_{a}^{x}} \\
{\left[\left(V_{s}^{i-1}\right)^{2}-\frac{3 \varepsilon \rho_{A}^{N} l_{s}}{2 d_{s} \rho_{s}}\left(V_{a}^{N}-V_{s}^{i-1}\right)^{2}\right]^{1 / 2} V_{s}^{i-1}>V_{a}^{x}}
\end{array}\right.
$$

\subsection{Coverage rate of the sandblasting jet}

During sandblasting, when abrasive particles are accelerated by the nozzle and arrived on the surface of the wind turbine blades, they will leave a dent on the surface of the materials due to the action of impact cutting. The dimensions of dent depend on the geometry and impact velocity of the abrasive particles. Studies on the coverage rate of the sandblasting jet are the basis for examining the sandblasting effect through testing later.

The abrasive particles used during sandblasting are irregular in shape, but their evenness index is large. The distribution range of granularity is narrow, and the dimensional distribution is even; thus, the abrasive particles are considered equivalent to spherical particles with a diameter of $d_{s}$ as per Rosin-Rammler distribution. Specifically, the abrasive particles impacted the surfaces of the wind turbine blades at a velocity of $V_{s}$ and formed a dent with a depth of $\mathrm{h}$ and a diameter of $D_{s}$. Fig. 5 shows a dent formed through blasting and impacting on the material by an individual abrasive particle.

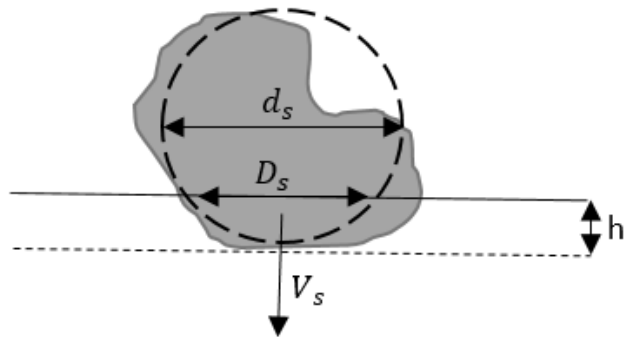

Fig. 5. Dent formed through blasting and impacting on material by an individual abrasive particle

The relationship among dent size, sandblasting time, sandblasting coverage rate, and abrasive flow resulted from impact cutting by abrasive particles and indicated in Formula (11) can be deduced on the basis of Avrami equation.

$$
t=-\frac{2 \bar{A} d_{s}^{3} \rho_{s} \ln (1-c)}{3 D_{s}^{2} \dot{m}}
$$

where $t$ is the shot blasting time, and its value is related to the velocity of the abrasive particle; $\bar{A}$ is the area to be sandblasted on the blade surface; c is the coverage rate; $D_{s}$ is the diameter of dent impacted by the particle.

The flow of abrasive particles is determined by the flow rate of the sand feeder during sandblasting, so such a value is assured. Therefore, the coverage rate of sandblasting is relevant to the sandblasting time if the particle diameter and density are determined.

$$
D_{s}^{2}=\frac{0.02931^{2} d_{s}^{2}\left(1-e^{2}\right)^{0.5} e^{0.5} v}{B^{0.5}}
$$

Substitute Equation (12) into Equation (11) and get:

$$
t=\frac{-2 d_{s}^{3} e \ln (1-c) B^{0.5}}{0.02931^{2} d_{s}^{2}\left(1-e^{2}\right)^{0.5} \rho^{0.5} v}
$$

Lastly, the functional relationship among coverage rate, sandblasting time, and abrasive velocity is arrived at:

$$
t=-\frac{2}{0.02931^{2}} \frac{D \sqrt{e^{B}}}{\sqrt{1-e^{2}}} \frac{\ln (1-c)}{v}
$$

\subsection{Model for experimental verification}

Sandblasting tests were conducted on Type LZ56.8-2.0 blades in Lianyungang Zhongfu Lianzhong Composites Group Co., Ltd. to verify the effect of various technological parameters on the micromorphology of the blade surface during sandblasting testing on wind turbine blades. Fig. 6 shows the blades used for the sandblasting test. During testing, different areas were manually sandblasted with a spray gun as per test requirements, and various technological parameters were adopted. Fig. 7 shows the test site.

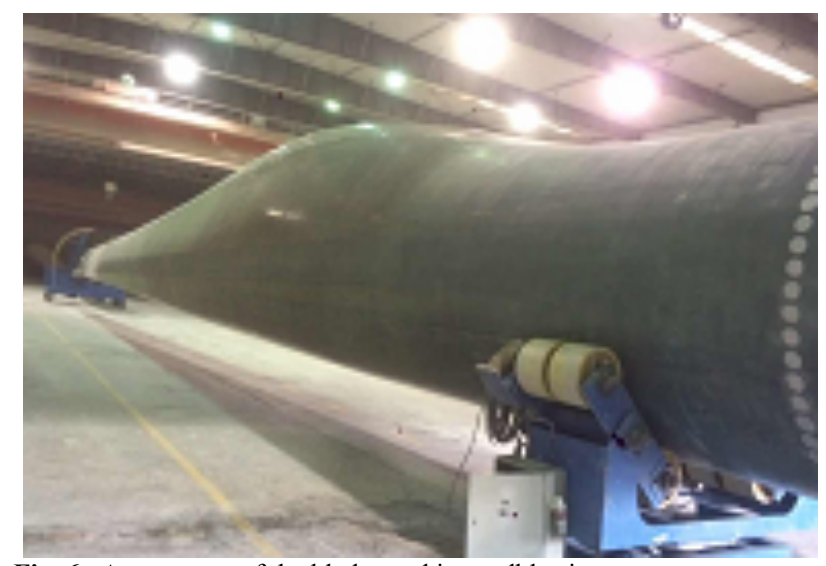

Fig. 6. Appearance of the blade used in sandblasting

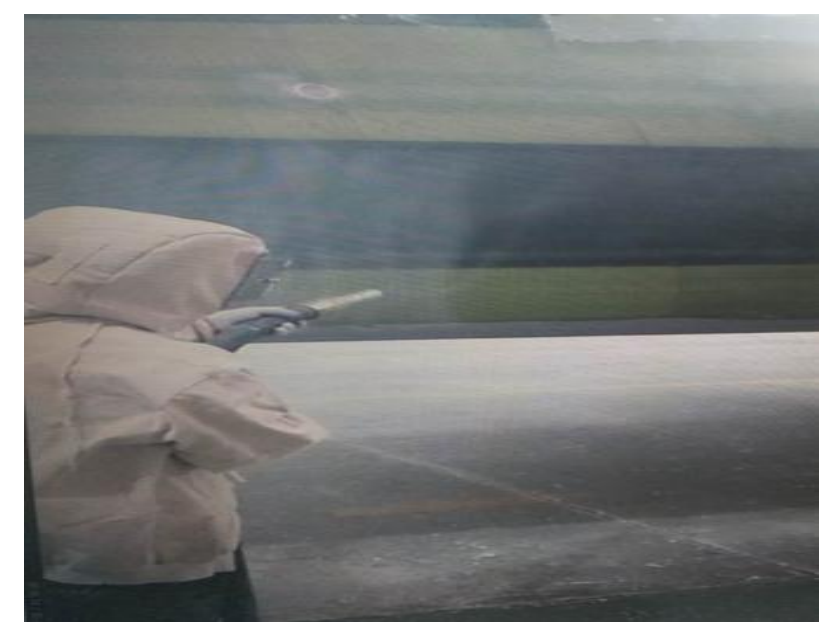

Fig. 7. Site for sandblasting testing

The ultimate aim of surface sandblasting on wind turbine blades is to increase the adhesion of the coating on the blade surface. Paint film adhesion tests were organized. Fig. 8 depicts the site for paint film adhesion tests. The approach used for tests is a cross-cut method. Fig. 9 shows the crosscuts in the site for paint film adhesion tests. The instrument used for adhesion tests is a DECCA-500 pull-off adhesion tester produced by the DECCA company. The instrument's 
range is $0-80 \mathrm{MPa}$, the resolution is $0.01 \mathrm{MPa}$, and both of which satisfied the test requirements.

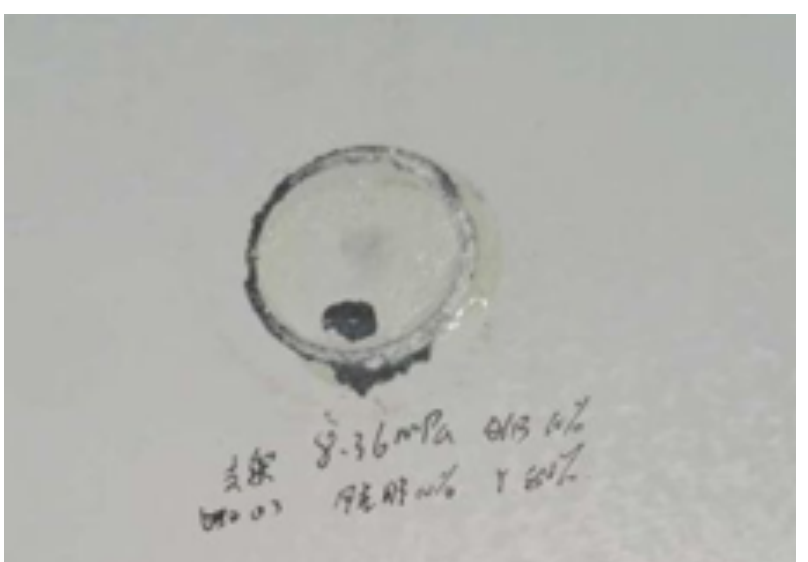

Fig. 8. Site for paint film adhesion test

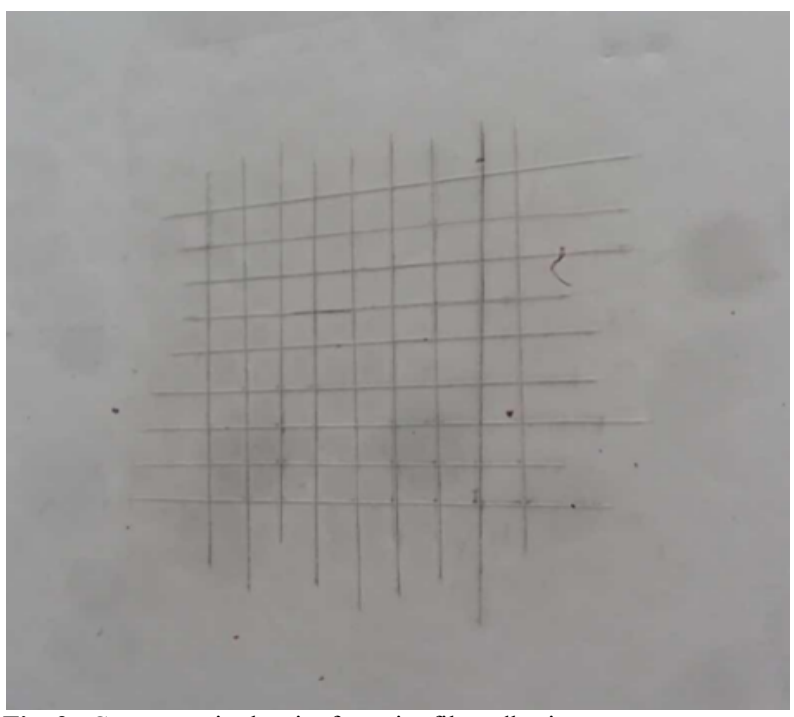

Fig. 9. Cross-cuts in the site for paint film adhesion test

\section{Result analysis and discussion}

\subsection{Distribution characteristics of gas and abrasive flow fields}

The theory of the simulation model for the biphasic flow of pneumatic sandblasting described in Section 3.2 demonstrates that the DPM based on the Euler-Lagrange method is suitable for studying the characteristics of the gas-solid biphasic flow during pneumatic sandblasting on wind turbine blades. This section is mainly designed to gain the flow fields of gas and abrasive. Moreover, this section analyzes the influences and mechanism of action on the flow fields of gas and abrasive when the technical parameters of pneumatic sandblasting are changed through a computer simulation. Fig. 10 illustrates the velocity distribution of gas on the axis.

Fig. 10 presents that the change tendency of the gas velocity on the axis is a course from low to high and gradually slows down. The reason for this event is demonstrated in Formula (10) in Section 3.3. Gas is compressed at the initial stage when it enters into the nozzle, and it is further accelerated due to its incomplete expansion at the diffusion part of the nozzle. A "velocity potential core" is formed after the gas left the nozzle, that is, the gas velocity is higher than the velocity of ambient air, and friction occurs between both. The external gas is continuously invading into the potential core, thereby decreasing the scope of the potential core and reducing the gas velocity. Therefore, the acceleration effect of gas that left the nozzle on the abrasive particle is limited, that is, it can speed up the abrasive particles only in a certain scope.
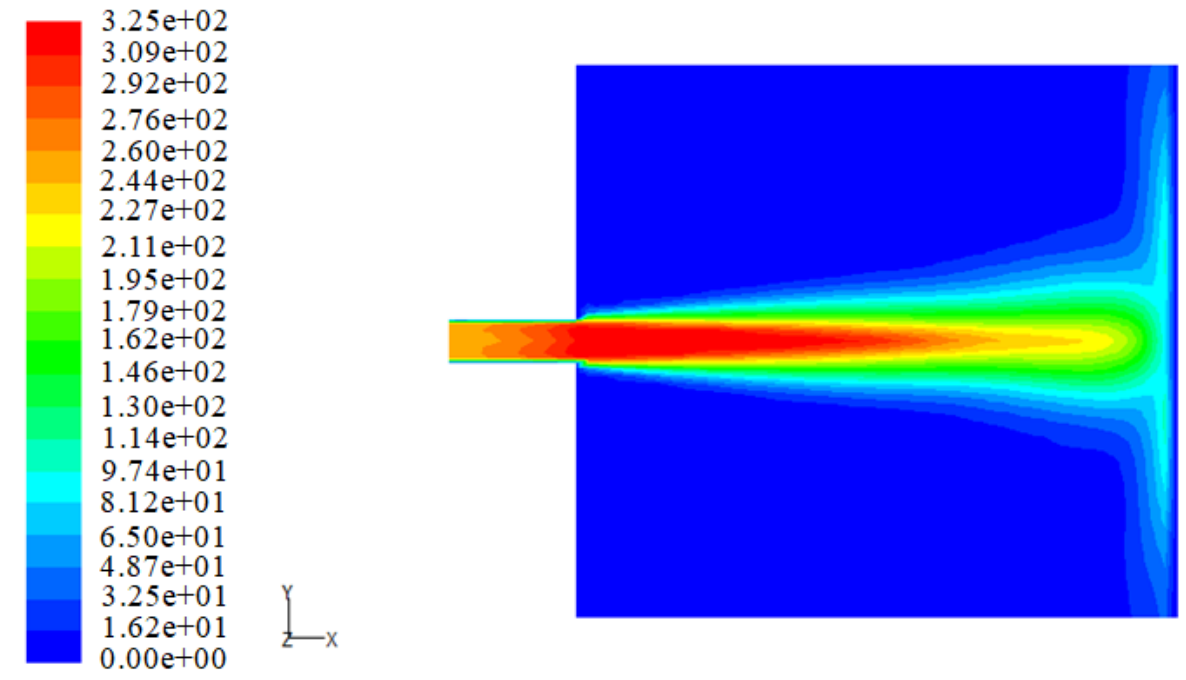

Contours of Velocity Magnitude $(\mathrm{m} / \mathrm{s})$

Jul 05,2019 FLUENT6.3(3d,pbns,dynamesh,ske)

Fig. 10. Axial velocity distribution of gas 

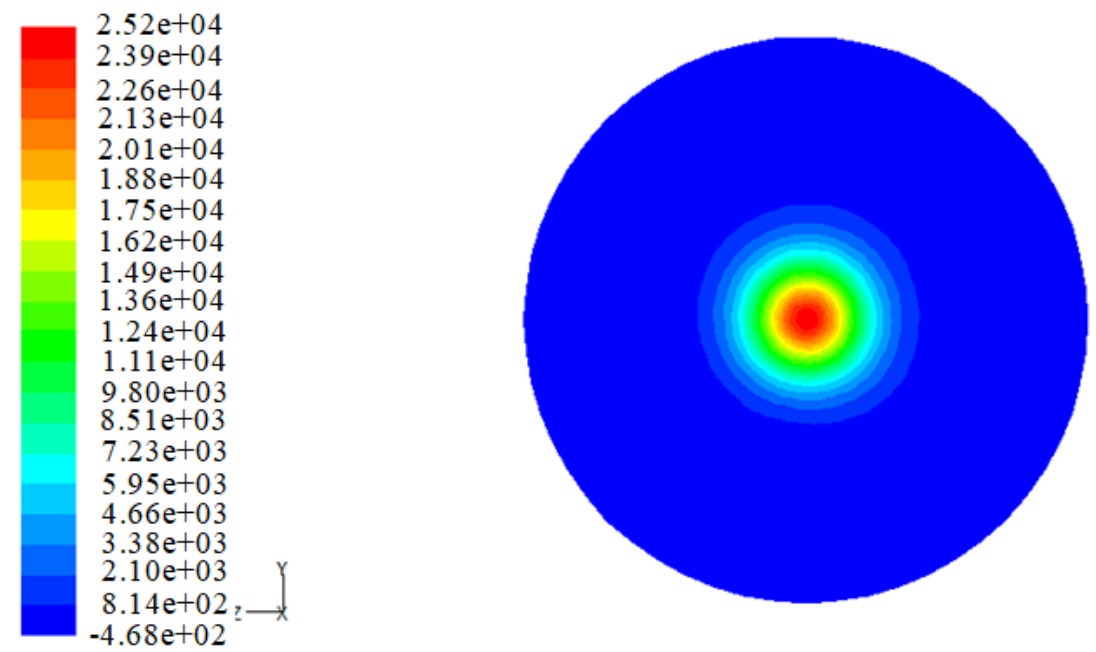

Contours of Static Pressure (pascal)

Jul 05,2019 FLUENT6.3(3d,pbns, dynamesh,ske)

Fig. 11. Radial velocity distribution of the abrasive particles

Fig. 11 shows that the velocity of the abrasive particles in the radial direction of the nozzle will be gradually reduced with the increase in diameter. The reason for this phenomenon is demonstrated in Formula (8) in Section 3.3. The velocity of the abrasive particles closest to the nozzle wall decreases with the enlargement of the nozzle diameter if the flow rates of abrasive particles are the same. Therefore, the nozzles shall be sized as per the current flow rate of abrasive particles.

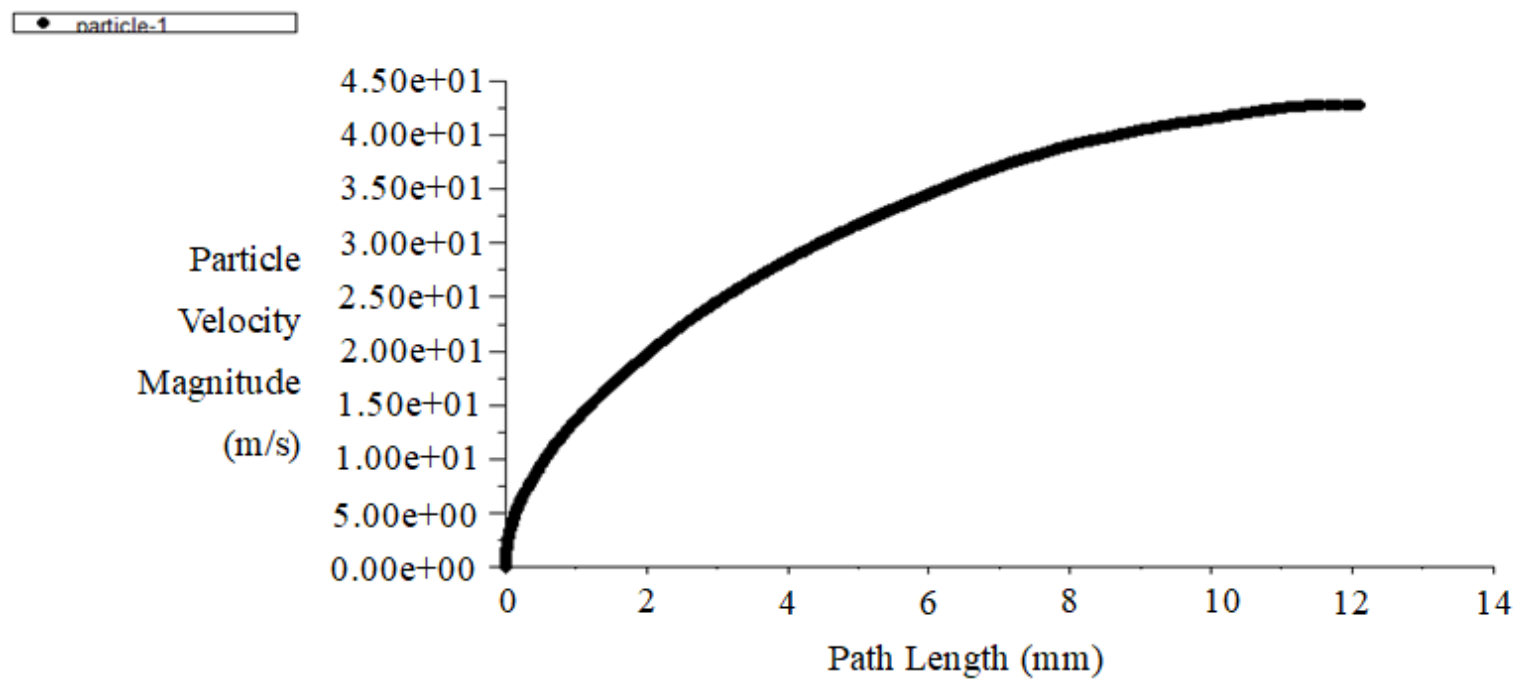

Particle Track

Jul 05,2019 FLUENT6.3(3d,pbns, dynamesh,ske)

Fig. 12. Axial velocity curve of the abrasive particles

Fig. 12 demonstrates that the velocity of abrasive particles in the axial direction of nozzle is gradually accelerated. Similar to the analysis shown in Fig. 10, the velocity of particles in the axial direction gradually accelerates. At the initial stage, the force acted on the abrasive particles is continuously speeding them up, and the acceleration is also fast. After the particles left the nozzle, the velocity of the gas itself in the scope of the potential core is no longer increased; thus, the increase of particle velocity is slow, and the curve becomes straight. The distance between the nozzle and the material surface is an important reference factor in the selection of nozzle parameters.

\subsection{Experiments on synthetic networks}

Adhesion tests (Table 4) are carried out to explore the influences brought by various technological parameters on the effects of sandblasting grinding. The test results demonstrate that the adhesion of particles is smaller, and the tendency of variations following the length of the nozzle and particle diameter is obscured when the pressure is low. This result indicates that the influence of nozzle length on adhesion is small. When the pressure is higher than 0.7 $M P a$, the adhesion is increased as the particle diameter expands. This phenomenon means that the pressure is the main influencing factor when it is low. The pressure and particle diameter are the main influencing factors when the pressure is high. 
Table. 4. Adhesion test

\begin{tabular}{c|c|c|c|c}
\hline Test no. & $\begin{array}{c}\text { Pressure } \\
P / M P a\end{array}$ & $\begin{array}{c}\text { Length of nozzle } \\
L / d m\end{array}$ & $\begin{array}{c}\text { Dia. of particle } \\
d / m m\end{array}$ & $\begin{array}{c}\text { Tested force } \\
F / M P a\end{array}$ \\
\hline 1 & 0.5 & 5 & 0.3 & 0.56 \\
2 & 0.5 & 7 & 0.1 & 0.58 \\
3 & 0.5 & 9 & 0.3 & 0.65 \\
4 & 0.6 & 5 & 0.2 & 0.68 \\
5 & 0.6 & 7 & 0.1 & 0.73 \\
6 & 0.6 & 9 & 0.3 & 0.87 \\
7 & 0.7 & 5 & 0.1 & 0.85 \\
8 & 0.7 & 7 & 0.3 & 0.81 \\
9 & 0.7 & 9 & 0.2 & 0.9 \\
11 & 0.8 & 5 & 0.1 & 0.86 \\
12 & 0.8 & 7 & & 0.82 \\
\end{tabular}

The diagrams of the SEM results for groups 2, 5, and 8 are assayed for further analysis of the influences of pressure on the ground surface through sandblasting. Table. 5 shows the sandblasted surfaces of blades under the action of various pressures. Table 4 shows that $\# 1$ and $\# 2$ are the test groups that are inferior to the test group of $0.7 \mathrm{MPa}$ in terms of the optimization of the technical parameters of pressure. The SEM graphs show that the number of dents is less, and deep dents are scarce. This finding means that the degree of damage on the blade surface is low when the pressure is low, thereby resulting in low roughness and adhesion. Meanwhile, \#3 is the test group at $0.7 \mathrm{MPa}$ for the optimization of the technical parameters of pressure. Evident dents can be found, and no broken fiber appeared. Many deep dents can be observed on the blade surfaces. The internal fibers are not damaged, and the strength of the blades is maintained.

Table 5. Sandblasted surface of blades under the action of various pressures

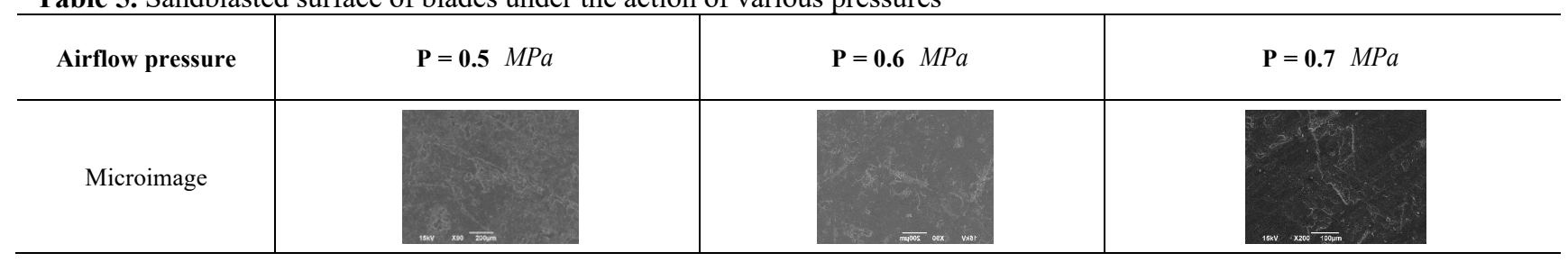

The SEM graphs for tests 7, 8, and 9 are analyzed to study the influences of particle diameter on the ground surface through sandblasting. The influences of various particle diameters on the blade surfaces are further analyzed. Table. 6 depicts the sandblasted surfaces of blades under the action of various particle diameters.

The airflow pressure of $0.7 M P a$ is selected as the optimized pressure parameter. The adhesion of these three test groups can meet the minimum requirements. Areas A and $\mathrm{B}$ at the same jet point are further analyzed. When the particle diameter is $0.1 \mathrm{~mm}$, evident dents appeared at the felt layer, and no fiber is broken in the SEM graphs formed through erosion by fast particles. The effect of sandblasting grinding is also enhanced. When the particle diameter is 0.2 $\mathrm{mm}$, evident dents appeared, and no fiber is broken in the SEM graphs. This finding indicates that the optimization of the particle parameters may influence the ground effect of sandblasting. When the particle diameter is $0.3 \mathrm{~mm}$, some fibers are broken and exposed in the SEM graphs. Consequently, the strength of the blade may be reduced. This phenomenon indicates that the oversized particles may result in excessive grinding and damage the blade.

Table 6. Sandblasted surface of blades under the action of various particle diameters

\begin{tabular}{|c|c|c|c|}
\hline Particle diameter & $\mathbf{d}=\mathbf{0 . 1} \mathrm{mm}$ & $\mathbf{d}=\mathbf{0 . 2} \mathrm{mm}$ & $\mathbf{d}=\mathbf{0 . 3} \mathrm{mm}$ \\
\hline Microimage & & & \\
\hline
\end{tabular}

\section{Conclusions}

A mathematical jet model for the blade surface sandblasting system was established in this study on the basis of Bernoulli's equation and Avrami formula to address issues, such as difficulty in determining the optimal technological parameters and low sandblasting efficiency in the process of sandblasting on wind turbine blades. The key technological parameters that affected the particle velocity during sandblasting on blade surfaces were obtained. Studies on the mechanisms of action for sandblasting on wind turbine blades were conducted by combining the numerical simulation technique and experimental research. Finally, the following conclusions could be drawn:

(1) The process of sandblasting on the surfaces of wind turbine blades is a course of mutual coupling action by multiple technological parameters. A reasonable optimization and selection of parameters will help increase the sandblasting efficiency and guarantee the adhesion of the coating on blade surfaces.

(2) The nozzle diameter, nozzle length, air pressure, particle diameter, and particle density are the key parameters 
that influence the effect of sandblasting on wind turbine blade surfaces.

(3) The influences of air pressure and particle diameter on the effect of sandblasting on wind turbine blade surfaces are significant. Air pressure and particle diameter are positively correlative to the velocity of abrasive particles within certain limits and to the sandblasting efficiency.

This study combined theoretical study and experimental analysis, proposed an optimized model, and analyzed the sandblasting technological parameters for pretreatment on wind turbine blade surfaces. The mathematical jet model established herein is simple and close to in-situ actual situations and provides a certain reference for studies on the relationship between surface characteristic parameters of blade materials and technological parameters of sandblasting. The model also enhanced the blade sandblasting efficiency and decision making for the optimization of the technological parameters for sandblasting. The actual data for the measurement of the blasting efficiency are scarce. Hence, data regarding the sandblasting efficiency will be integrated and corrected, and this model will expand the understanding of the law of the sandblasting grinding mechanism on wind turbine blade surfaces.

This is an Open Access article distributed under the terms of the Creative Commons Attribution License

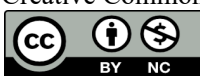

\section{References}

1. Wang, Y., Yu, Zh., Li, K., Hu, J., "Effects of surface properties of titanium alloys modified by grinding, sandblasting and acidizing and nanosecond laser on cell proliferation and cytoskeleton". Applied Surface Science, 501(19), 2020, pp. 21-23.

2. Pawlik, M., Lu, Y., Le , H., "Effects of surface modification and graphene nanoplatelet reinforcement on adhesive joint of aluminium alloys". International Journal of Adhesion and Adhesives, 99(41), 2020, pp. 34-41.

3. Huang, W., Xiong, R., Luo, Y., "Simulation for velocity control of pneumatic sandblasting flow on the inner wall of plastic-coated pipes". Computer simulation, 36(01), 2019, pp. 230-234.

4. Li, J., Jiang, H, Du, F., Liu, L., Zhao, Sh., "Influences of pneumatic sandblasting technology on wettability effect of 304 stainless steel surface". China Surface Engineering, 30(05), 2017, pp. 95-101.

5. Wang, Ch., He, Sh., Zhang, Er., Li, D., "Multi-scale analysis and representation of sandblasted surfaces". Surface Technology, 44(06), 2015, pp. 127-132.

6. Liao, K., Huang, X., Gong, H., Zhang, X., Chen, H., Zhong, L., "Influences of coverage rate of sandblasted surfaces on surface integrity of 7075 aluminium alloy". Transactions of Materials and Heat Treatment, 39(08), 2018, pp. 122-128.

7. Zhang, L., "Analysis and researches on coverage rate of shot blasted surfaces". Master thesis of Soochow University, China, 2015, pp.22-27.

8. Wang, K., Han, X., Zhang, X., Liu, Y., Chen, J., "Design and simulation of supersonic de Lava nozzles". Chinese Journal of Construction Machinery, 9(03), 2011, pp. 304-308.

9. Luo, J., Zeng, G., Li, B., "FLUENT-based Simulation and analysis of biphasic flow field for nozzle orifice types". Modular Machine Tool \& Automatic Manufacturing Technique, (10), 2016, pp. 44-47.

10. Kirk D., Abyaneh M. Y., "Theoretical Basis of Shot Peening Coverage Control". The Shot Peener, 9(2), 1995, pp. 28-30.
11. Kirk D., "Theoretical Principal of Shot Peening Coverage". The Shot Peener, 19(2), 2005, pp. 24-26.

12. Suyitno, Arifvianto,B., Widodo,T., Mahardika,M., Dewo,P., Salim,U., "Effect of cold working and sandblasting on the microhardness, tensile strength and corrosion resistance of AISI 316L stainless steel". International Journal of Minerals Metallurgy and Materials, 19(12), 2012, pp. 1093-1099.

13. Hensel,J.,Eslami,H.,Nitschke-Pagel,T.,Dilger,K., "Fatigue Strength Enhancement of Butt Welds by Means of Shot Peening and Clean Blasting". Metals, 9(7), 2019, pp. 137-139.

14. Choi,D.,Kim,T.,Yang,C.,Nam,J.,Park,J., "Discrete element method and experiments applied to a new impeller blade design for enhanced coverage and uniformity of shot blasting". Surface \&amp; Coatings Technology, 367(6749), 2019, pp. 230-231.

15. Singh,A.,S. Ghosh,S. Aravindan, "Influence of dry micro abrasive blasting on the physical and mechanical characteristics of hybrid PVD-AlTiN coated tools". Journal of Manufacturing Processes, 37(89), 2019, pp. 10-11.

16. Draganovská,D., Ižaríková,G., Guzanová,A., et al., “General Regression Model for Predicting Surface Topography after Abrasive Blasting.". Abrasive Blasting, 8(11), 2018, pp. 31-32.

17. Li,K.,Xie,J.,Chen,D.,Ma,Y.,Guo,D.,Shao,B., Li,CH., Dong,J.,Cao,P., Yoon,J.., "Observation of magnetic properties and microstructural evolution of 301 stainless steel upon ultrasonic shot peening". Materialia, 10(9), 2020, pp. 10-11.

18. Bo,W., Xin,X., Chen, Y., Dong, M., Wang, W., "Simulation and analysis on erosion Venturi type nozzles for pneumatic sandblasting". Natural gas \& Oil, 37(05), 2019, pp. 91-97.

19. Thomas PJ, "Simulation of industrial processes for control engineers". Oxford: Butterworth-Heinemann, United Kingdom, 1999, pp.42-44.

20. Kalide, W., "Einfuhrung in die technische Stromungslehre". Munchen: Carl Hanser Verlag, Germany, 1990, pp.51-64. 